\title{
Research on Management Transforms of Enterprise Human Resources in Big Data Era
}

\author{
Jing Ren \\ Business School, Xi'an Peihua University, Xi’an, 710000, China
}

Keywords: Big data, Human resources, Management transforms

\begin{abstract}
The arrival of the big data era brings opportunities and challenges for all walks of life, and provides a new angle of view for human resource management. Traditional human resource management has the problems of backward ideas, low tools and inaccurate forecasts. This paper discusses the countermeasures of concept updating, tools improvement and prediction optimization of human resources management based on big data to provide some references for the relevant researchers.
\end{abstract}

\section{Introduction}

Great influence and value of big data itself contains not only will directly lead to innovative industries, but also for the national governance and corporate decision-making and personal life, work and thinking and other aspects will have far-reaching effects. Big data is associated with the growing popularity of network behavior, containing data producers, real intentions, preferences, non-traditional structures and meanings of data. At the same time, for enterprises, this influence will be directly related to the relevant strategy and management details. Human resource management has become the key to improve the core competitiveness of enterprises, and is facing the challenges of the rapid development of the big data era. With the rapid development of Internet technology and information industry, the era of big data has arrived, which brings great business opportunities to enterprises. Big data is a need for new processing mode to have more decision-making power, insight, discovery capabilities and process optimization capabilities of mass, high growth rate and diversified information assets. Understanding data, using data, and believing data will become a new driving force for enterprise development, as well as an urgent need for business managers, and human resource management cannot stay out of it. Due to the large data fully, and can crawl, timely refresh and other characteristics, can accurately guide the allocation of resources in many areas, regardless of work or daily life, all cannot do without the support of big data. In enterprise management, many companies begin to use big data to integrate and manage talents. In human resources work, when the number of people is particularly large, the big data on personnel structure, future development and talent support will be positive.

\section{Problems of Enterprise Human Resources Management in Big Data Era}

Backward Concepts of Human Resources Management. The era of big data to a certain extent affected and changed the mode of human resource management, however, in the practice of human resource management, human resource management part of workers out of habit still use the traditional concept of human resource management work, this effect failed to recognize data of external environment brings to the enterprise human resources management, accustomed to focus on the enterprise, that the day-to-day affairs of the internal management of enterprise human resources management is the enterprise, only to their own environment as a reference to the formulation and implementation of policies related to human resources, neglecting the big data of the current pattern of the era, the data selection is mostly based on the subjective judgment of the way, part of the data is 
ignored in the premise of not by comparison of audit. Such a way is unreasonable and unscientific. HR should change the traditional ideas and practices of filtering and processing data and processing and processing useful information in a data way. This is one of the major problems that need to be solved by the human resource management department. The next big data era of innovation of enterprise human resources management mode depends on the management idea renewal, ideas and attitudes change only when managers, action to change management, finally formed, which led to the innovation of management mode. However, due to the inertia of thinking on the part of human resources management is still in the traditional the concept of human resource management to carry out the work, the era of big data enterprise human resources management environment and the traditional human resource management environment failed to correct understanding of different, accustomed to focus on the enterprise, the enterprise human resources management is defined as the routine management of enterprises, enterprise environment for reference only to the formulation and implementation of relevant human resource policy. Ignore the current pattern of the era of big data. They do not realize that the full understanding and use of the data platform will help companies win the competition.

Low-end Tools of Human Resources Management. With the big data, cloud computing, information technology is widely used in various fields, compared to human resources management is dwarfed. Traditional human resource management departments still rely mainly on subjective judgment in dealing with data and information. The quality of staff and performance evaluation results are seldom evaluated from the perspective of combination of qualitative and quantitative methods, and the management efficiency is very low. The development of Internet and e-commerce concepts and practices. This brings opportunities to the innovation of human resource management mode. Faced with the arrival of such an information age, human resources management must keep pace and be good at using modern tools. This also brings great pressure and challenge to the innovation and optimization of human resource management methods in the era of big data. Although the continuous development of network information technology provides great convenience for personnel selection, training and management, it also intensifies the competition among talents. Because the speed of information development is much faster than the speed of talent selection and training, it leads to job hopping of some enterprises and increases the gap of talents in enterprises. Different from the traditional personnel training mode, the era of big data, the use of information technology makes the training speed and efficiency are guaranteed, it is because of the selection, training and management of network information technology for the enterprise personnel to provide a great convenience, so that between enterprises more fierce competition, however, due to personnel selection and the train speed is far below the pace of development of information technology, and lead to the talent gap, which in turn caused the talent competition, talent competition in the information technology and the interaction situation, how to retain talent and cultivate excellent talents to become the enterprise human resources managers must consider the problem.

Inaccurate Prediction of Human Resources Management. At present, the human resource management information system is difficult to predict and predict in the future human resource trends, the growth of employees and the tendency to leave the job. In the big data concept under the occupation career planning is based on all the data, so the information collection, the human resources department to understand their position and promotion will occupation planning of structured and unstructured data. We must dig deeper and other information related to the occupation career planning, to ensure the integrity of information and integrity, then the information quantification, abandon part of the interference data, eventually forming a three-dimensional employee information set, the location of occupation planning and occupation guide more targeted and persuasive. The enterprise can use software technology to develop and design a set based on the idea of big data evaluation of the occupation career management system for occupation career management in the traditional take its essence, to its dregs, occupation career management and big data together, play the advantages of the two. The general human resources demand forecast can adopt the qualitative forecast and quantitative forecast of two kinds of methods, including empirical prediction method, qualitative description method, quantitative prediction regression forecast method 
and ratio analysis and trend forecasting method. A qualitative method of these methods in subjective strong, controlled level is weak. The prediction accuracy is low; the other is the large amount of data, statistical analysis chart method of complex iterative process, which belongs to the quantitative research method, but this method in the data visualization and data processing technology under the situation of the prevalence is relatively complicated to use big data technology to implement human resource prediction results with the actual situation as far as possible is a hot topic of current research.

\section{Countermeasures of Management Transforms of Enterprise Human Resources in Big Data Era}

Update Concepts of Human Resources Management. The era of big data, enterprise human resources management must be combined with the requirements of openness, establish an open mind, information technology and human resources management truly combine to ensure the vision control in the understanding of management level; at the same time, the importance of human resource management in the era of big data, completes the enterprise internal employee advocacy work, promote the effective learning and communication in the big data platform. In the era of big data development environment, we must fully use network technology to support its recruitment, planning and training management of human resources, and truly implement it in all aspects of it. The enterprise must adhere to the people-oriented principle, and as a core concept of talent management; at the same time, in the personnel selection, training and management, we must establish the data management, provide real effective platform for the realization of their own value for employees, and to ensure the common development of enterprises and employees. Therefore, in the era of big data, enterprises must make full use of the Internet has brought great convenience, the establishment of human resource management information system, through the effective integration of information technology and management technology, to provide decision support for the enterprise strategic target realization, provide the most direct and effective service for the related personnel. The recruitment is carried out by many resumes and forms of documents, and the reform of the era of big data led enterprises to take full advantage of the Internet to carry out recruitment, and guarantee to find the most suitable and satisfactory talent in the short term. The recruitment information, put forward higher requirements for enterprises, businesses must establish a website, and the establishment of recruitment Web page on the website, the registration information required for job seekers and text, job seekers can download and registration according to the demand.

Improve Tools of Human Resources Management. Human resource management is to maximize the potential of employees, to ensure the realization of organizational goals and to maximize the development of members, based on mastering the information of employees. In the big data environment, the enterprise can collect information, grasp the basic personal information of every employee, including education, work experience, family information and other basic data and solving problems, to complete the daily work efficiency of unstructured, then the flow condition and the blueprint for the development goals and development needs of the staff and the enterprise personnel combined with the human resources department can make static analysis objectively through these data, the number of employees of the company's quality and structure, liquidity of personnel to make accurate dynamic analysis. Human resources management specialist can also through the big data structure analysis, understand each employee's work ability and good field, to perform their duties. In the era of big data, human resources management system will be close to the ordinary staff, to produce more interactive data, so that employees can better participate in the organization of personnel management work to establish a more standardized work processes. The most important core assets of an enterprise. All the information companies, everything can be stored by the data form, analyze and export by effective management model. Through the fact and data form, the objective grasp of the situation of human resources, determine the focus of future human resources management, and formulate specific programs and plans, based on the facts, based on data. In the past, human resource management departments mainly used expert evaluation and comprehensive evaluation methods to evaluate talents, and this evaluation method was often subjective and prone to the primacy effect. The era of big data talent evaluation way come from the 
analysis of the test of all kinds in the evaluation period. We can obtain a more objective, humane and reference high evaluation results to help the human resource department more objective selection of talents. If the enterprise training plan, incentive system, employee promotions and salary increases are big data to the employee's work performance generated as the foundation, we can improve the objectivity and fairness of the enterprise incentive mechanism, to make enterprise incentive system more convincing and ensure the stability of personnel.

Optimize Prediction of Human Resources Management. In the environment of large data, through the collection of information inside and outside the organization, managers can accurately grasp the data of each employee's real situation. In the understanding of the basic situation, employee education information, internships or work experience, common interests and hobbies such as structured and unstructured data, solve the problem of aging, competition and other non-structured data and staff ability: the task completion efficiency and performance results of the efficiency of data and potential data, combined with the staff personal goals and development needs and enterprises in recent years the flow of human resources situation, the human resources department can make static analysis of objective quantity, quality and structure of employees, make precise dynamic analysis of personnel liquidity, the number of vacancies forecast demand at any time, to see which of them can post to fill through internal training, which must be obtained through the enterprise external recruitment positions. The main task of human resource planning is to predict people's needs. At present, the main tools used include expert forecasting, regression analysis, trend analysis and ratio analysis. When managers use these tools, most of them are subjective and cannot be comprehensive and objective, while the arrival of big data era can solve this problem well. Through the collection, statistics and analysis of the data and the strategic objectives of the enterprise, the human resources department will formulate the future human resource planning. In accordance with such principles, all personnel decisions in enterprises are carried out in the form of facts and data, not only can objectively determine the focus of future human resources work, but also can determine specific programs and plans. The human resources department should make good use of the data and make correct use of the data. Every step of the planning should be based on facts and data. This will have an immeasurable impact on the establishment, implementation and implementation of personnel policies in enterprises.

\section{Conclusion}

In this society dominated by knowledge economy, big data has become the symbol of the development of the times. Therefore, human resource managers must change their own ideas, build a complete and effective human resources management system, and apply large data technology to optimize the management of human resources.

\section{References}

[1] Wang Jiaren. Modern Enterprises Human Resources Management Innovation Based on the "Internet +" and Big Data Era [J]. Heilongjiang Science, 2016, 7(5): 152-153.

[2] Xi Nan, Li Yuming, Peng Jianfeng, et al. From e-HRM to Big Data HRM: The Evaluation of Human Resource Data Management- A Case of Tencent [J]. Human Resources Development of China, 2017(5): 79-88.

[3] Kang Yuqi. Big Data in Human Resource Management: Roles and Applications [J]. Tianjin Science \& Technology [J]. 2015, 42(3): 7-8.

[4] Wang Qun, Zhu Xiaoying. Thinking of innovation in enterprise human resource management in big data age [J]. Journal of Shenyang University of Technology (Social Science Edition), 2015, 8(3): 255-259. 